\title{
Characterization of Peanuts After Dry Roasting, Oil Roasting, and Blister Frying.
}

Xiaolei Shi ${ }^{a}$, Jack P. Davis ${ }^{\text {bc }}$, Zhoutong Xia ${ }^{a}$, K.P. Sandeep ${ }^{a}$, Timothy H. Sanders ${ }^{b}$, Lisa O.

$\operatorname{Dean}^{b^{*}}$

${ }^{a}$ Department of Food, Bioprocessing and Nutrition Sciences, North Carolina State University, Schaub Hall, Raleigh, NC 27695, USA

${ }^{\mathrm{b}}$ USDA, Agricultural Research Service, Market Quality and Handling Research Unit, 236

Schaub Hall, North Carolina State University, Raleigh, NC 27695, USA

${ }^{\mathrm{c}}$ Current Address: JLA Global International, Albany, GA, 31721, USA

*Corresponding author: Lisa.Dean@ars.usda.gov.

Keywords: peanut, oil roasting, dry roasting, microstructure, shelf life

\begin{abstract}
Peanuts were systematically deep fried, blister fried, or dry roasted at $177^{\circ} \mathrm{C}$ to Hunter Lvalues of $53.0 \pm 1.0,48.5 \pm 1.0$, and $43.0 \pm 1.0$, corresponding to light, medium, and dark roasting, respectively. Thermal modifications of the epidermal and parenchyma cells were observed in the scanning electron microscopic images for processed peanuts, compared to raw peanuts. Peanut microstructure was most extensively damaged by blister frying, followed by
\end{abstract}


deep frying, and then dry roasting. The moisture content decreased with increased surface color, due to more moisture loss with longer heat processing time. For light roasting, blister fried peanuts had significantly higher moisture contents than the deep fried and dry roasted peanuts, while for medium and dark roasting, blister fried had lower moistures than the other two. Descriptive sensory analysis was able to distinguish the flavor and texture profiles of peanuts prepared by different roasting methods. In storage testing throughout 16 weeks, peroxide value measurements indicated the blister fried peanuts had the longest shelf life, followed by the dry roasted, and then the deep fried. Descriptive sensory analysis proved that the rate of the loss of roast peanut flavor during storage was faster in dry roasted peanuts followed by blister fried and deep fried. 


\section{Introduction}

In the U.S.A., the majority of peanuts grown are converted into value-added products utilizing the entire seed, such as peanut butter, confections, and snack products. For such purposes, peanut kernels are usually thermally processed as the first step in the manufacture of the final products to achieve a specific flavor, color, and texture (Perren \& Escher, 2013). Peanuts are processed typically by dry roasting or oil roasting, and to a lower extent by boiling, microwave heating, or a combination of multiple processing methods (Woodroof, 1983; Young, Schadel, \& Heertje, 1993). Dry roasting is performed by heating the food material using hot air without the use of oil or water as a carrier. The most commonly used oil roasting methods for peanuts are deep frying and blister frying. Blister frying has not been scientifically defined but according to cooking instructions, this process involves the steps of boiling blanched peanuts in water for a certain time, draining the excess water, and then deep frying the soaked kernels in vegetable oil, resulting in a highly crispy, highly crunchy snack with blisters on the kernel surface (Miyagi, 2013). Although there are several commercial products prepared by dry roasting, deep frying, and blister frying, the scientific comparison of different roasting methods has not been reported.

Roasting is defined as the heat treatment at temperatures above $125^{\circ} \mathrm{C}$, at which nonenzymatic reactions occur to form pigments with specific yellow-brown color (Kleinert, 1966). During roasting, color has been extensively used as a quick and non-destructive indicator of food quality for certain foods, especially for roasted coffee beans, hazelnuts, almonds, and peanuts (Baggenstoss, Poisson, Kaegi, Perren, \& Escher, 2008; Kaftan, 2012; Ozdemir et al., 2001; Pattee, Giesbrecht, \& Young, 1991). Different temperature and roasting time combinations were 
able to achieve the equivalent peanut surface colors (McDaniel, White, Dean, Sanders, \& Davis, 2012; Smith, Perry, Marshall, Yousef, \& Barringer, 2014). McDaniel and coworkers (2012) found that, at a given color, moisture contents decreased with decreasing roast temperatures due to the longer roast times required for the same color formation. It was also found that peanuts roasted at lower temperatures had higher tocopherol contents. Another study investigating oven, microwave, and combination roasting suggested that significant differences were observed with flavor attributes for peanuts roasted to equivalent colors by different roasting methods; however, no significant differences were found in free fatty acid or peroxide values (Smith, Perry, Marshall, Yousef, \& Barringer, 2014). Also, different roasting methods may cause different types of and/or alter the extent of thermal modifications (e.g. cell wall rupture, protein body distension, and cytoplasmic network disruption) to the microstructure of peanut kernels (Young, et al., 1993).

The method of roasting is known to affect the physical, chemical, sensory, as well as the storing properties of roasted peanuts. As oil roasting is a faster roasting process than dry roasting, the best way to compare different roasting methods should be based on the concept of equivalent color roasting instead of equivalent roasting time. The process of blister frying involves an initial soak of the raw peanuts in water which could result in loss of soluble protein and sugars which are involved in peanut texture and roasted flavor. The objective of this study was to systematically compare the effects of different roasting methods on the peanut quality related properties, including moisture content, nutritional content, microstructure, and sensory properties, as well as storability, at equivalent surface colors in order to identify what qualities can be controlled in order to produce high quality peanut products. 


\section{Materials and methods}

\subsection{Materials}

Jumbo grade size peanuts ( $>21 / 64$ on a slotted screen) of the Georgia 06G cultivar, a high-yielding, large-seed, runner-type variety, were obtained during the 2013 harvest from the USDA ARS National Peanut Laboratory (Dawson, GA, USA). The peanuts had been cured, shelled, sized using standard screens, blanched and stored utilizing standard industry practices prior to delivery to the USDA ARS Market Quality \& Handling Research Unit at North Carolina State University (Raleigh, NC, USA). A pilot plant scale roaster previously described (Poirier, Sanders, \& Davis, 2014) built by the Bühler Aeroglide Corporation (Cary, NC, USA) with an adjustable air flow rate (up to $1.27 \mathrm{~m} / \mathrm{s}$ ), air flow direction, bed depth, and temperature control (up to $204^{\circ} \mathrm{C}$ ) was used for the dry roasting. The air flow direction was changed from up-flow to down-flow at the half point of the roasting time. Following roasting, the roasting tray containing the peanuts was placed onto a forced air blower for cooling to ambient temperature. A pilot plant scale fryer (Vulcan-Hart, Baltimore, MD, USA) holding $16 \mathrm{~L}$ of pure peanut oil (Ventura, Brea, CA, USA) was used for deep frying and blister frying. Following frying, the peanuts were spread onto a fine mesh steel screen with a cooling fan installed above for cooling to ambient temperature. The batch size for deep frying and blister frying was $2 \mathrm{~kg}$ of peanuts per batch.

The peanuts were dry roasted, deep fried, or blister fried at $177^{\circ} \mathrm{C}$ to three equivalent surface colors (Light, $\mathrm{L}=53.0 \pm 1.0$, Medium, $\mathrm{L}=48.5 \pm 1.0$, and Dark, $\mathrm{L}=43.0 \pm 1.0$ ) as determined by a Hunter Lab Model D25 colorimeter (Hunter Lab Associates, Reston, VA, USA). Processing times were determined using the linear regression on the preliminary curves of the 
Hunter L-values versus roasting time. The time used for each treatment was summarized in Table 1. Blister frying was conducted by immersing the peanuts in boiling water for $10 \mathrm{~min}$, followed by deep frying. After cooling, the roasted peanuts were placed into glass jars, and stored frozen $\left(-26^{\circ} \mathrm{C}\right)$ until further analysis.

\subsection{Color distribution}

Single seed color of 100 blanched kernels for each treatment was measured using the Hunter Lab scale with a Model DP-301 Chroma Meter (Minolta Camera Co., Ltd. Japan). The percentage of the single seed color within an interval of $\mathrm{L}=2.5$ was calculated by JMP Pro 10.0 (SAS, Cary, NC, USA) and plotted in lightness (L) distribution charts (Fig. 1).

\subsection{Protein content of rinse water}

A CE Instruments NA 2100 Protein Analyzer (Thermo Finnigan, Milan, Italy) was used for analysis of total nitrogen using combustion analysis and thermal conductivity detection (TCD). The apparatus was equipped with a Model AS128 auto-sampler, a combustion oven containing the oxidation catalyst and a reduction oven containing copper, traps for carbon dioxide and water containing soda lime and anhydrous magnesium perchlorate, respectively, and a GC column packed with active carbon and a thermal conductivity detector. The TCD temperature was set at $60{ }^{\circ} \mathrm{C}$ and the pressure was $1200 \mathrm{~Pa}$. An analytical portion (100 mg) of phenylalanine was used for calibration. A portion of the rinse water $(500 \mu \mathrm{L})$ used to soak the peanuts prior to blister frying was added to metal capsules and loaded into the autosampler for nitrogen measurement. 


\subsection{Sugar content of rinse water}

The rinse water used to soak the peanuts prior to blister frying was analyzed for sugar content using a Dionex BioLC HPLC system (Dionex Corporation, Sunnyvale, CA, USA) at a controlled temperature of $25^{\circ} \mathrm{C}$ (Pattee, Isleib, Giesbrecht, \& McFeeters, 2000). The system consisted of a gradient pump, an autosampler, and a Pulsed Amperometric Detector (PAD). The column used was a Dionex PA-1, $250 \mathrm{~mm}$ length and $4 \mathrm{~mm}$ i.d., fitted with a Dionex PA-1 Guard column. Aliquots of the rinse water were spiked with an internal standard solution containing lactose and cellobiose (Sigma-Aldrich, St. Louis, MO, USA). The solutions were passed through a syringe fitted with a Dionex OnGuard ${ }^{\circledR}$ II H Filter into autosampler vials. An external standard solution was prepared containing myo-inositol, glucose, fructose, sucrose, raffinose, stachyose and the internal standards. Sugars were identified through comparisons of retention time of unknown samples to known standards. Sugar contents were calculated from the chromatogram peak heights relative to the internal standards. All sugar standards were purchased from Sigma-Aldrich (St. Louis, MO, USA).

\subsection{Moisture content}

Whole peanut seeds from each treatment were analyzed in triplicate using a forced air oven at $130{ }^{\circ} \mathrm{C}$ for $6 \mathrm{~h}$ to determine the moisture content (MC) (Young et al., 1982). The weight differences before and after oven incubation were compared to dried mass for MC.

\subsection{Microstructure}


Individual peanut seeds were cut with a clean razor blade to create either a $1-1.5 \mathrm{~mm}$ thick cross-section profile of $1 / 4$ of the seed or trimmed to provide a 2 to $3 \mathrm{~mm}^{2}$ surface profile. Approximately 8 pieces per sample were placed into a solution of cold $3 \mathrm{~mL} / 100 \mathrm{~mL}$ glutaraldehyde in $0.05 \mathrm{~mol} / \mathrm{L} \mathrm{KPO}_{4}$ buffer $(\mathrm{pH} 7.0)$ and stored for approximately $5 \mathrm{~d}$ at $4{ }^{\circ} \mathrm{C}$. Samples were rinsed in three $1 \mathrm{~h}$ changes of $0.05 \mathrm{~mol} / \mathrm{L} \mathrm{KPO}_{4}$ buffer $(\mathrm{pH} 7.0)$ followed by $24 \mathrm{~h}$ changes of 30,50,70, 95 and $100 \mathrm{~mL} / 100 \mathrm{~mL}$ ethanol/water, while cooling in an ice bath. The samples were then warmed to room temperature, and dehydration was completed using two additional $24 \mathrm{~h}$ room temperature changes of pure ethanol. All samples were critical point dried for 15 min in liquid $\mathrm{CO}_{2}$ (Tousimis Samdri-795, Tousimis Research Corporation, Rockville, MD, USA). Samples were mounted on stubs with double-stick tape and silver paint, sputter coated with approximately $50 \AA$ gold-palladium (Hummer 6.2 sputtering system, Anatech U.S.A., Union City CA, USA) and stored in a vacuum desiccator. Samples were viewed at $15 \mathrm{kV}$ using a JEOL JSM-5900LV scanning electron microscope (JEOL U.S.A., Peabody, MA, USA).

\subsection{Descriptive sensory analysis}

Descriptive sensory panels were conducted at the USDA ARS Market Quality and Handling Research Unit (Raleigh, NC, USA). Sensory analysis was conducted every 4 wk until 16 wk after roasting. Prior to testing, samples were equilibrated to ambient room temperature. Duplicates of the roasted samples were evaluated by well-trained panelists $(n>6)$ in randomized order. A peanut lexicon based on Johnsen, Civille, Vercellotti, Sanders \& Dus (1988) with modifications by Sanders, Vercellotti, Crippen, \& Civille (1989) and Schirack, Drake, Sanders, $\&$ Sandeep (2006) was used. The texture lexicon, containing terms of crispy, crunchy, hardness, and breakdown was built by the panel with terms commonly used to describe the texture of 
oilseed and nuts (Civille, Lapsley, Huang, Yada \& Seltsam, 2010). Crispy was described as the amplitude of the high-pitched sound associated with mastication with the incisors. Crunchy was the amplitude of the low-pitched sound associated with mastication with the molars. Hardness was the amount of force required to break through the sample with the molars. Breakdown was the ease of which the sample was broken as it was chewed with the molars. The Spectrum ${ }^{\mathrm{TM}}$ Method (Sensory Spectrum, Inc., Chatham, NJ, USA) was used for the training and evaluation sessions.

\subsection{Peroxide value}

Peroxide values (PV) were determined using AOAC method 965.33 (AOAC, 1990). In brief, peanuts were coarsely ground and compressed using a Carver Model 3912 hydraulic press (Carver, Inc., Wabash, IN, USA) to express the oil. Oil aliquots of $5.00 \pm 0.05 \mathrm{~g}$ were weighed into $250 \mathrm{~mL}$ flasks and dissolved using $30 \mathrm{~mL}$ of acetic acid-chloroform solvent mixture (3:2 v/v). Then, $0.5 \mathrm{~mL}$ saturated $\mathrm{KI}$ was added into the flask. After $1 \mathrm{~min}$ of shaking, $30 \mathrm{~mL} \mathrm{H}_{2} \mathrm{O}$ was added, followed by the addition of $0.5 \mathrm{~mL}$ starch solution $(1 \mathrm{~g} / 100 \mathrm{~mL}$ water) as indicator. The solution was titrated by 0.01 or $0.001 \mathrm{~N} \mathrm{Na} \mathrm{S}_{2} \mathrm{O}_{3}$ until blue color just disappeared. The PVs were calculated by the equation of $\mathrm{PV}=\mathrm{S} \times \mathrm{N} \times 1000 / \mathrm{W}$, where $\mathrm{S}$ is the volume of $\mathrm{Na}_{2} \mathrm{~S}_{2} \mathrm{O}_{3}$ used for titration, $\mathrm{N}$ is the normality of $\mathrm{Na}_{2} \mathrm{~S}_{2} \mathrm{O}_{3}$, W is the oil mass in $\mathrm{g}$. All chemicals and reagents used were purchased from Thermo Fisher Scientific (Fairlawn, NJ, USA).

\subsection{Statistical analysis}

Results from triplicate experiments were analyzed using JMP PRO 10.0 (SAS, Cary, NC, USA). Factorial analysis of variance (ANOVA) and least-squares means (LSMEANs) student's 
$\mathrm{t}$ test was conducted on the color distribution, MC, and sugars. One-way ANOVA was performed on the results of the sensory analysis. A significance standard of $\alpha=0.05$ was used.

\section{Result and discussion}

\subsection{Lightness (L) distribution}

The color distribution of 100 blanched kernels prepared by each roasting method at equivalent light medium and dark surface colors is represented in Fig.1. Each block in this figure represents the probability that the surface color of a single seed is within the corresponding color range. The probability distribution was fitted as a normal distribution. Statistical analysis indicated that there was no significant evidence of an interaction between roasting method and the surface color. Under the experimental conditions presented here, the degree of roast significantly contributed to the different Hunter L-values of blanched peanut kernels $(\mathrm{p}<0.001)$. For each roast degree, there was no evidence that one roasting method was significantly different in color from another roasting method. Also, the distribution dispersion $(\sigma)$ was close for all of the roasts, indicating the uniformity of roasting could not be differentiated.

\subsection{Microstructure}

The scanning electron microscopic (SEM) images of the raw peanut outer rounded surface showed that it is composed of well aligned rectangular epidermal cells (Fig. 2. A). This image was very similar to the one previously published (Young \& Schadel, 1990). The outer region of the cross section of the raw peanut kernel was seen to be composed of a single layer of epidermal cells $[\mathrm{E}]$ and parenchyma cells $[\mathrm{P}]$ (Fig. 2. B). The granules inside the parenchyma 
cells are lipid bodies, protein bodies, and starch grains. The size of protein bodies has been reported to be 5 to $12 \mu \mathrm{g}$ in diameter and the starch grains, 4 to $15 \mu \mathrm{g}$ in diameter (Young \& Schadel, 1990). The lipid bodies are reported to be smaller with a diameter about 1 to $2 \mu \mathrm{g}$ (Yatsu, 1981). The membrane of the granules formed a continuous, dense cytoplasmic network. In this study, as most of the oil was removed during the fixation step, therefore, the large granules seen were assumed to be starch and protein bodies, although they were not distinguishable by SEM (Young \& Schadel, 1991).

The SEM images of the outer surfaces of the roasted peanut kernels are compared in Fig. 3. Damage to the kernel surface was observed in the images of the deep fried peanuts. The damaged region exposed the inner parenchyma cells. With the increase in color intensity due to longer roasting times, almost all cytoplasm was lost from the cells. For the blister fried peanuts, there was more extensive damage to the layer of epidermal cells. In those damaged regions, almost all cells were lost from the cytoplasm. The rinse water from soaking the peanuts prior to blister frying was found to have a protein content of $2.52 \pm 0.03 \mathrm{mg} / \mathrm{mL}$ and a total sugar content of $3.98 \pm 0.26 \mathrm{mg} / \mathrm{mL}$. This represented losses of $2.5 \mathrm{~g}$ of the protein in $100 \mathrm{~g}$ of the whole raw peanuts and $4.0 \mathrm{~g}$ of sugars from $100 \mathrm{~g}$ of raw peanuts to the water used to presoak the peanuts. Although the protein loss was minimal $(<10 \%)$, most of the free sugars were lost which was expected to have some effect on the flavor. In the dry roasted peanuts, no obvious epidermal damage was observed, but with the increase in the color intensity due to the longer roasting time, there was a higher degree of deformation of the epidermal cells from the well-aligned rectangle to irregular shape. As for the outer region of the cross section of peanut kernels (Fig. 4), there was no obvious difference among the different roasting colors for each roasting method, although the darker dry roasted peanuts showed a higher degree of cell wall rupture. When 
compared across the different roasting methods, the deep fried and the dry roasted kernels showed comparable changes to the cell structures, mainly in cytoplasmic network disruption. Comparable changes in the peanut microstructure during oil and dry roasting have been reported (Young \& Schadel, 1990; Young, et al., 1993). An extensively damaged cell structure was observed for blister frying, resulting in a considerable number of empty cells depleted of granules. The blister fried peanuts also showed cell wall rupture and disruption of the cytoplasmic network.

\subsection{Moisture effects}

The moisture contents of the raw and roasted peanuts are displayed in Fig. 5. The MC decreased from the initial value of $5.66 \mathrm{~g} / 100 \mathrm{~g}$ based on dry weight in the raw peanuts to final values of 0.85 to $1.64 \mathrm{~g} / 100 \mathrm{~g}$ in the roasted peanuts. The MC decreased with the increased surface color, due to the increasing moisture losses with longer heat processing time (McDaniel et al., 2012). The initial MC of peanuts prepared for blister frying was the highest as the peanuts were immersed in boiling water prior to deep frying. This also resulted in the blister fried peanuts of the light roasting intensity having a higher MC than the deep fried and the dry roasted peanuts. With the extended processing time of blister frying, the water release from the kernels was seen to cause more extensive damage to the cell structures (Fig. 3). The damaged areas of the epidermal cells was attributed to this additional moisture loss and resulted a lower MC in both the medium and dark colored blister fried peanuts.

\subsection{Descriptive sensory analysis}


Radar plots were used to describe the sensory properties of processed peanuts (Figs. 6 and 7). The flavor profiles included the attributes of roasted peanutty (RP), sweet aromatic, dark roast, raw beany, woody, sweet, bitter, and astringency. The panelists were not able to distinguish differences in the astringency of the samples. For the other attributes, when the peanuts were dry roasted or fried to the light color intensity, the deep fried and the blister fried peanuts had similar flavor profiles, though the blister fried peanuts had higher RP and dark roast flavors. The dry roasted peanuts had higher dark roast flavor intensities, lower raw beany, and higher woody and bitterness. When the peanuts were medium roasted or fried, the dry roasted peanuts also showed higher dark roast intensity and lower raw beany flavors, as well as higher bitterness. When the peanuts were dark roasted or fried, the flavor profiles for all three roasting methods were similar to each other. Across the three roasting colors, RP tended to increase with the increase of roast color intensity from light to dark, but the positive attribute of sweet aromatic had no significant increase.

The texture profiles were composed of the attributes of crispy, crunchy, hard, and breakdown (Fig. 7). The texture profile patterns were similar across the three roast intensities of light, medium, and dark. In general, the blister fried peanuts were found to have the highest crispiness, crunchiness, hardness, and the lowest breakdown. The deep fried peanuts were found to have higher crispiness and hardness values than the dry roasted peanuts. The highest breakdown was observed in the dry roasted peanuts at the light roast intensity, but there were no significant differences in the breakdown of the deep fried and dry roasted peanuts at the medium and dark roast intensities.

\subsection{Peroxide value}


$\mathrm{PV}$ is the measure of the concentration of peroxides and hydroperoxides formed in the initial stages of lipid oxidation. The end of the shelf life was considered to be the time at which the PV reached $10 \mathrm{meq} / \mathrm{kg}$ of oil. The raw peanuts stored under the same conditions as the roasted samples had the lowest PV throughout the $16 \mathrm{wk}$ of storage and remained below 5 meq/kg oil (data not shown). For each roasting method, there was a trend that the lighter roasted or fried peanuts had higher PV than the darker intensities, especially during the first $12 \mathrm{wk}$ of storage (Fig. 8). This indicated that the dark roasted peanuts were less prone to lipid oxidation. This is explained by a hypothesis that there may be more antioxidants formed during thermal processing for darker samples that protected the samples from oxidation (McDaniel et al., 2012). The PV increased steeply in the deep fried peanuts for the first eight wk, then decreased at a similar rate from wk 8 to wk 12 , and then showed minor increases from wk 12 to wk 16 . As PV measures only the primary products formed in the initial stages of lipid oxidation, the decreases after $8 \mathrm{wk}$ were attributed to the decay of primary products in the latter stages of lipid oxidation. As the first measurement during the storage test was made at wk 4 and at this time point the PV was already much higher than $10 \mathrm{meq} / \mathrm{kg}$ oil, the shelf life for the deep fried peanuts was determined to be $1 \mathrm{wk}$ using the linear regression of $\mathrm{PV}$ from the data achieved from wk 0 to wk 4. For the blister fried peanuts, PV remained lower than $20 \mathrm{meq} / \mathrm{kg}$ oil for the entire testing period, indicating they were less prone to lipid oxidation than the deep fried and dry roasted peanuts. The PV of the light and medium blister fried peanuts exceeded $10 \mathrm{meq} / \mathrm{kg}$ oil at wk 4 , but the dark blister fried peanuts remained less than $10 \mathrm{meq} / \mathrm{kg}$ oil for the first $12 \mathrm{wk}$. For the dry roasted peanuts, the PV increased progressively for the initial $4 \mathrm{wk}$, but decreased slightly for medium and dark dry roasted samples. As with the deep fried peanuts, the slight decrease was attributed to the decay of primary products during the latter stages of lipid oxidation. 


\subsection{Flavor stability}

The flavor of the roasted peanut samples was not found to be as sensitive as PV as a measure of storage life. The flavor changes were not reported until the PV reached 30 to $40 \mathrm{meq} / \mathrm{kg}$ oil. For the roasted peanutty (RP) flavor attribute, all the samples showed progressive decreases throughout the $16 \mathrm{wk}$, regardless of the roasting method and color intensities (Fig. 9). Although the PV of the blister fried peanuts remained at a low level, the RP decreased significantly for the light and medium color intensity blister fried peanuts. The decrease in the RP of the dark blister fried peanuts was minor until $12 \mathrm{wk}$. Another positive attribute, sweet aromatic remained stable throughout the $16 \mathrm{wk}$ of storage and showed a small increase for the blister fried peanuts from 4 wk to 12 wk (Fig. 9). Two negative attributes highly associated with the lipid oxidation during storage are cardboardy and painty. Similar patterns were observed from the curves of the cardboardy and painty attributes as a function of storage time (Fig. 10). The general intensity ranking of the cardboardy attribute for each time point was dry roast $>$ blister fry $>$ deep fry. It was not until $12 \mathrm{wk}$ that there was a significant increase in the cardboardy intensity. As for the painty attribute, the intensity remained low for the blister fried and the deep fried peanuts. For the dry roasted peanuts, the intensity of the painty attribute remained at a low level for the first 8 wk of storage. The light intensity dry roasted peanuts showed the largest increase of the painty

attribute from the 8 wk point, while the medium and dark intensity of the dry roasted peanuts had the largest increase in this attribute at $12 \mathrm{wk}$ of storage.

\section{Conclusion}

Peanut roasting for consumer products is most commonly done by using either a dry roasting or an oil roasting process. These methods can achieve similar color in the final products by 
adjusting time and/or temperature. Dry roasting produced the least surface damage and blister frying resulted in the greatest damage with subsequent removal of nutrients, especially sugars. Flavors, textures and shelf life, as defined by the onset of off flavors or flavor fade of roasted peanut flavor, will vary with the roasting method and with the final roast color. As the roast color became darker, there was less loss of RP flavor with storage time. Oil roasted peanuts were found to have faster onset of rancidity measured chemically (PV) due to the increased surface oil. The dry roasted were found to have higher levels of off flavors as the MC were higher which plays a role in other types of lipid oxidation. The textures of the roasted products were also affected by MC with the oil roasted types having harder textures and lower MC. Type of roasting, final moisture, degree of roast and cellular damage were all found to play a role in the final characteristics of roasted peanuts..

\section{Acknowledgements}

commercial, or not-for-profit sectors.

Mention of trade names or commercial products is solely for the purpose of providing specific information and does not imply recommendation or endorsement by the U.S. Department of Agriculture.

\section{References}

AOAC. (1990). Official methods of analysis of the Association of Official Analytical Chemists, $15^{\text {th }}$ ed., K. Helrich (ed.), Arlington, VA, USA, Association of Official Analytical Chemists. 
Baggenstoss, J., Poisson, L., Kaegi, R., Perren, R., \& Escher, F. (2008). Coffee roasting and aroma formation: Application of different time-temperature conditions. Journal of Agricultural and Food Chemistry, 56(14), 5836-5846.

Civille, G.V., Lapsley, K., Huang, G., Yada, S., \& Seltsam, J. (2010). Development of an almond lexicon to assess the sensory properties of almond varieties. Journal of Sensory Studies, 25(1), 146-162.

Kaftan, A. (2012). Kinetics of color degradation in thermal processed almond. International Proceedings of Chemical, Biological \& Environmental Engineering, 33(51), 265.

Kleinert, J. (1966). Einige aspekte der kakaobohnenröstung. Gordian, 66, (1579), 3-17.

Johnsen, P.B., Civille, G.V., Vercellotti, J.R., Sanders, T.H., \& Dus, C.A. (1988). Development of a lexicon for the description of peanut flavor. Journal of Sensory Studies, 3(1), 9-17.

McDaniel, K. A., White, B. L., Dean, L. L., Sanders, T. H., \& Davis, J. P. (2012). Compositional and mechanical properties of peanuts roasted to equivalent colors using different time/temperature combinations. Journal of Food Science, 77(12), C1293-1299.

Miyagi, A. (2013). Improving oxidative stability of deep-fried peanuts by frying under appropriate process conditions in a greater stability medium. Journal of Food Processing and Preservation, 37(5), 701-708. 
Ozdemir, M., Seyhan, F. G., Bakan, A. K., Ilter, S., Ozay, G., \& Devres, O. (2001). Analysis of internal browning of roasted hazelnuts. Food Chemistry, 73(2), 191-196.

Pattee, H. E., Isleib,T. G., Giesbrecht, F. G., \& McFeeters, R.F. (2000). Investigations into genotypic variations of peanut carbohydrates. Journal of Agricultural and Food Chemistry, 48(3), 750-756.

Pattee, H. E., Giesbrecht, F. G., \& Young, C. T. (1991). Comparison of peanut butter color determination by Cielab L A B And Hunter color-difference methods and the relationship of roasted peanut color to roasted peanut flavor response. Journal of Agricultural and Food Chemistry, 39(3), 519-523.

Perren, R., \& Escher, F. E. (2013). Impact of roasting on nut quality. In L. J. Harris (Ed.), Improving the safety and quality of nuts (pp. 173-197). Philadelphia, PA, USA, Woodhead Publishing.

Poirier, D., Sanders, T. H., \& Davis, J. P. (2014). Salmonella surrogate reduction using industrial peanut dry roasting parameters. Peanut Science, 41(2), 72-84.

Sanders, T.H., Vercellotti, J.R., Crippen, K.L., \& Civille, G.V. (1989). Effect of maturity on roast color and descriptive flavor of peanuts. Journal of Food Science, 54(2), 475-477.

Schirack, A.V., Drake, M., Sanders, T.H., \& Sandeep, K.P. (2006). Impact of microwave blanching on the flavor of roasted peanuts. Journal of Sensory Studies, 21(4), 428-440. 
Smith, A. L., Perry, J. J., Marshall, J. A., Yousef, A. E., \& Barringer, S. A. (2014). Oven, microwave, and combination roasting of peanuts: comparison of inactivation of salmonella surrogate Enterococcus faecium, color, volatiles, flavor, and lipid oxidation. Journal of Food Science, 79(8), S1584-1594.

Woodroof, J. G. (1983). Peanuts : production, processing, products. Westport, CN, USA, AVI Publishing.

Yatsu, L. (1981). Cell-wall architecture of peanut (Arachis hypogaea L.) cotyledon parenchyma cells and resistance to crushing. Journal of the American Oil Chemists' Society, 58(2), A148A150.

Young, C. T., \& Schadel, W. E. (1990). Microstructure of peanut seed - A review. Food Structure, 9(4), 317-328.

Young, C. T., \& Schadel, W. E. (1991). Microstructure of peanut (Arachis hypogaea L. cv. Florigiant) cotyledons after oil cooking. Journal of Food Science, 56(1), 76-79.

Young, C. T., Schadel, W. E., \& Heertje, I. (1993). A comparison of the effects of oven roasting and oil cooking on the microstructure of peanut (arachis-hypogaea L. cv florigiant) cotyledon. Food Structure, 12(1), 59-66. 
Young, J. H., Whitaker, T. B., Blankenship, P. D., Brusewitz, G. H., Troeger, J. M., Steele, J. L., \& Person, N. K. (1982). Effect of oven drying time on peanut moisture determination. Transactions of the ASAE, 25(2), 491-496.

\section{Figure captions}

Fig. 1. Single seed color distribution of deep fried, blister fried, and dry roasted peanuts at equivalent light, medium, and dark surface colors.

Fig 2. Scanning electron micrograph of unroasted peanut. Figure (A) is the scanning electron micrograph of epidermal cells on the raised outer rounded surface of a raw peanut cotyledon. Figure (B) represents the scanning electron micrograph of the cross section of outer surface of epidermal cells (Arrow E) and subtending parenchyma cells (Arrow P) of a raw peanut cotyledon.

Fig. 3. Scanning electron micrograph of deep fried, blister fried, and dry roasted peanut cotyledons of light, medium, and dark surface colors on the outer rounded surface. Images were taken at locations with damaged epidermal cells for deep fried and blister fried peanuts. Arrow [B] is the bodies of protein or starch; arrow [cp] is the cytoplasm network; arrow [v] is the emptied space; arrow $[\mathrm{w}]$ is the cell wall; arrow $[\mathrm{G}]$ is the guard cell. 
Fig. 4. Scanning electron micrograph of deep fried, blister fried, and dry roasted peanut cotyledons of light, medium, and dark surface colors at the cross section. Arrow [cp] is the cytoplasm network; arrow [v] is the emptied space; arrow [E] is the epidermal cells; arrow [s] is the space between parenchyma and cell wall in parenchyma cells.

Fig. 5. Moisture content of blanched peanuts as a function of roasting method.

Fig. 6. Flavor profile analysis of light roasted peanuts prepared by deep frying, blister frying, and dry roasting.

Fig. 7. Texture profile analysis of dark roasted peanuts prepared by deep frying, blister frying, and dry roasting.

Fig. 8. Peroxide values of deep fried, blister fried, and dry roasted peanuts at light, medium, and dark surface colors during storage at ambient room temperature.

Fig. 9. Sensory intensities of roasted peanutty, sweet aromatic, cardboard, and painty flavor attributes in deep fried, blister fried, and dry roasted peanuts during storage at ambient room temperature. 

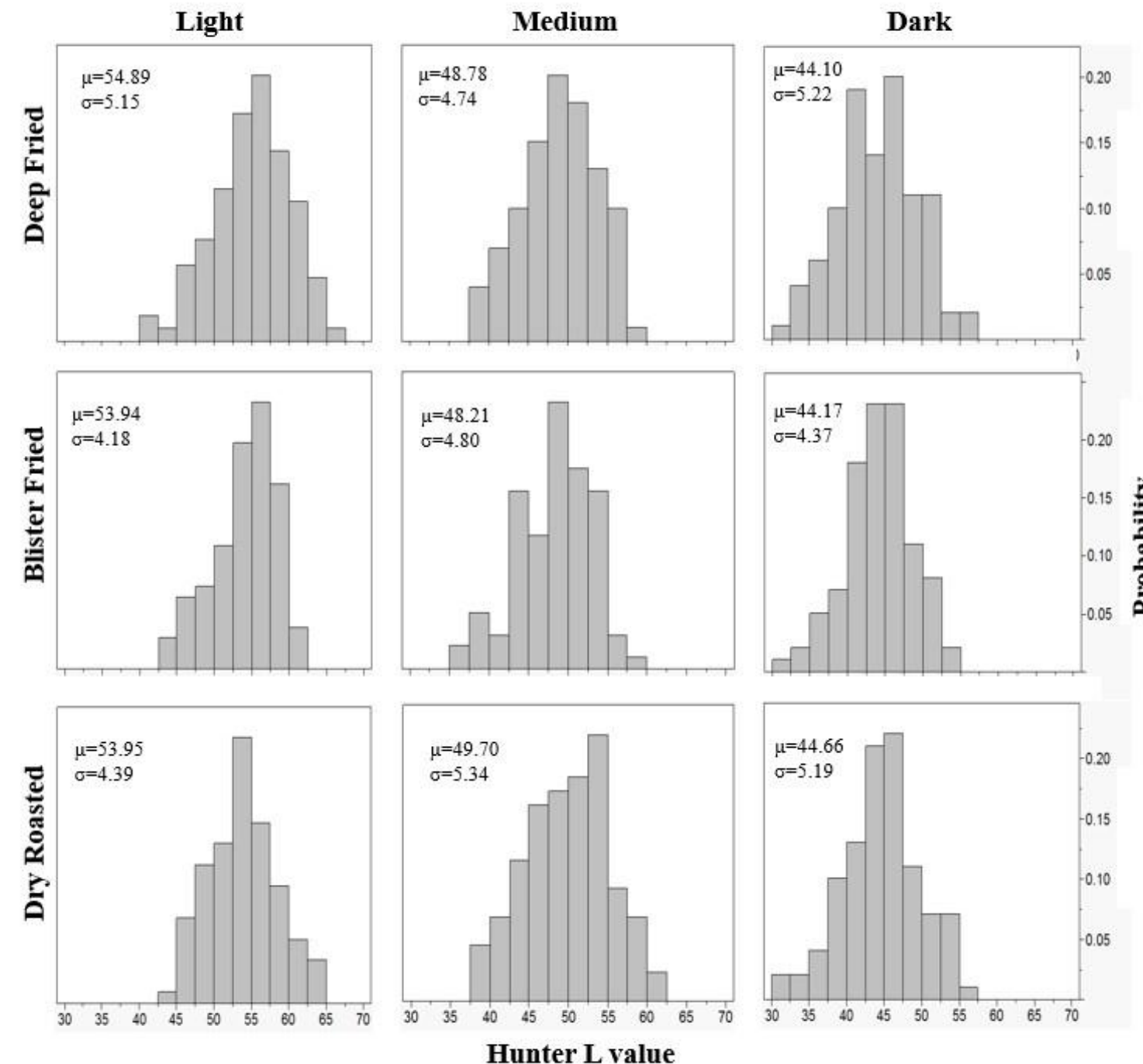

Hunter L value 
Epidermal

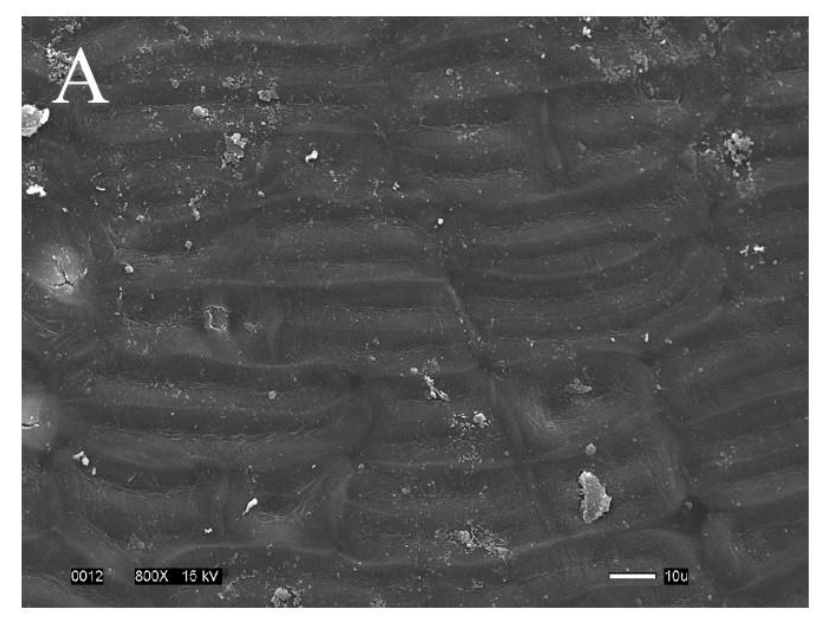

\section{Outer}

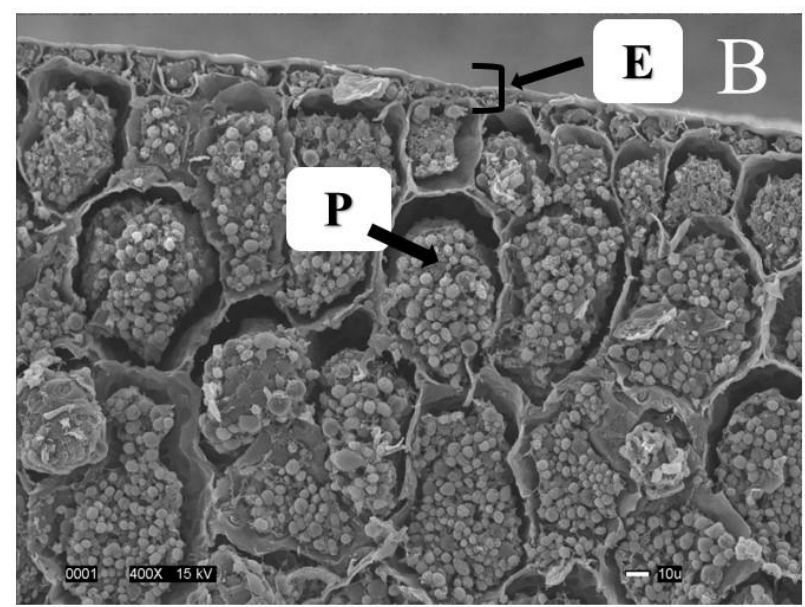



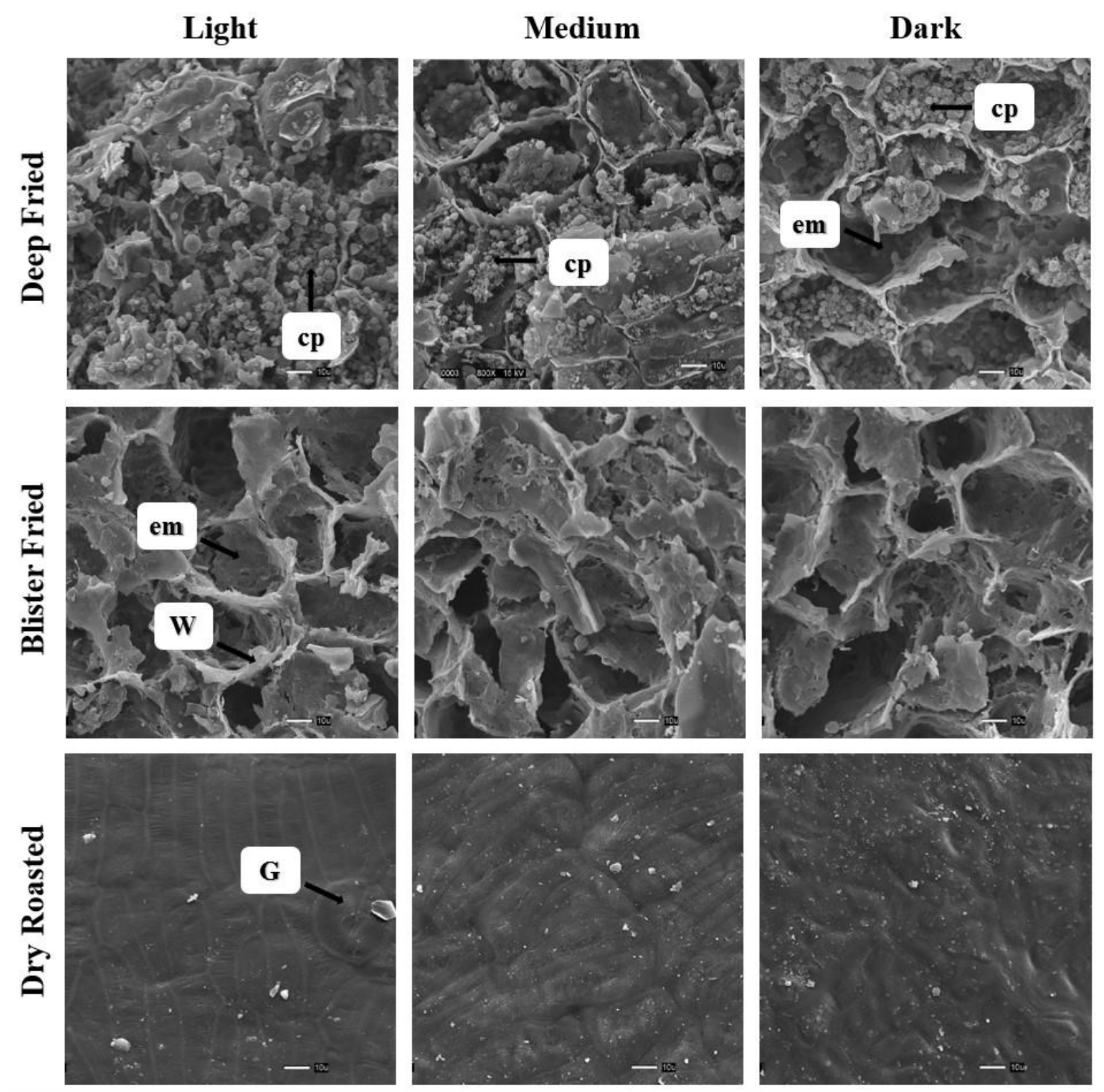

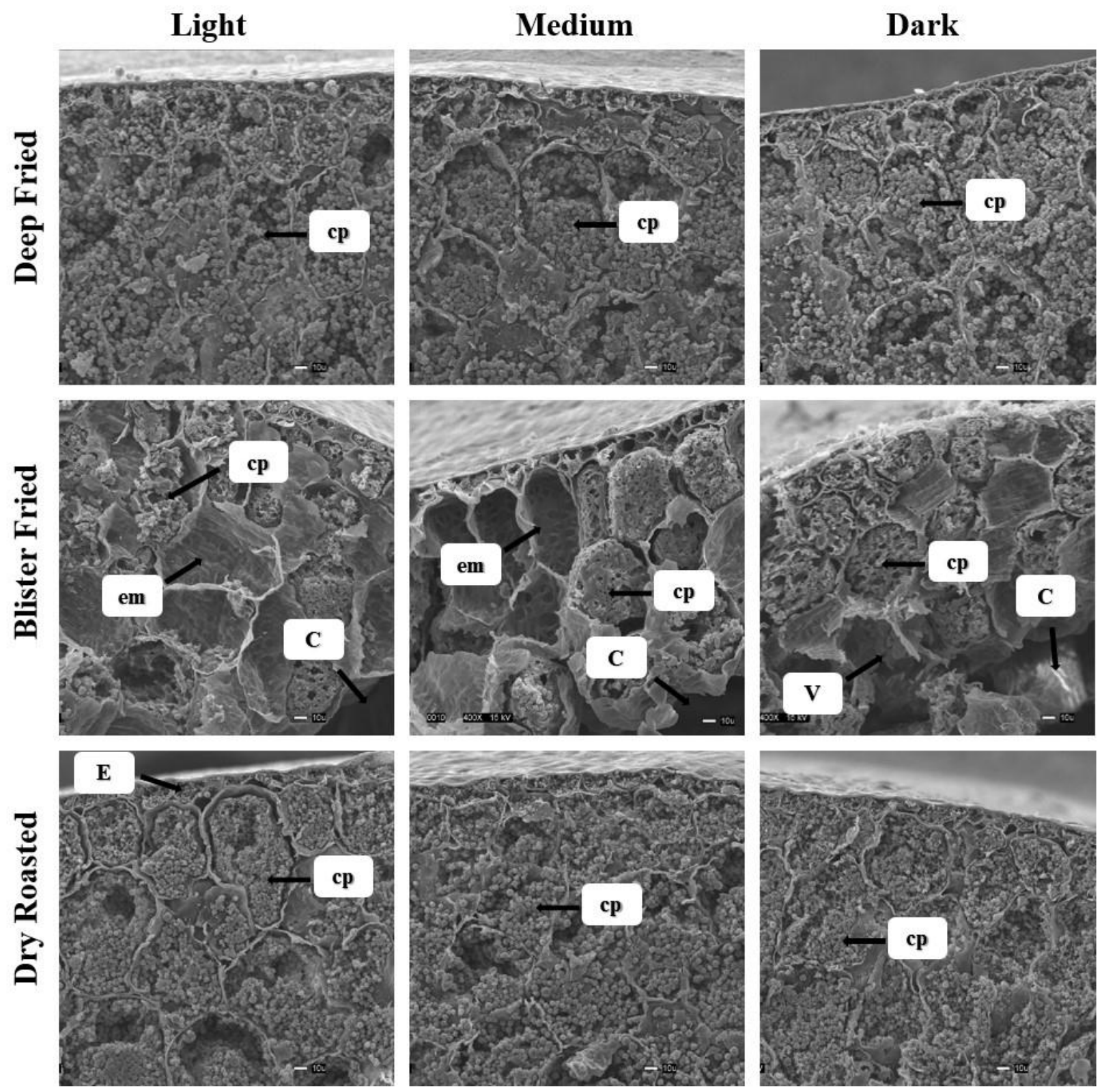


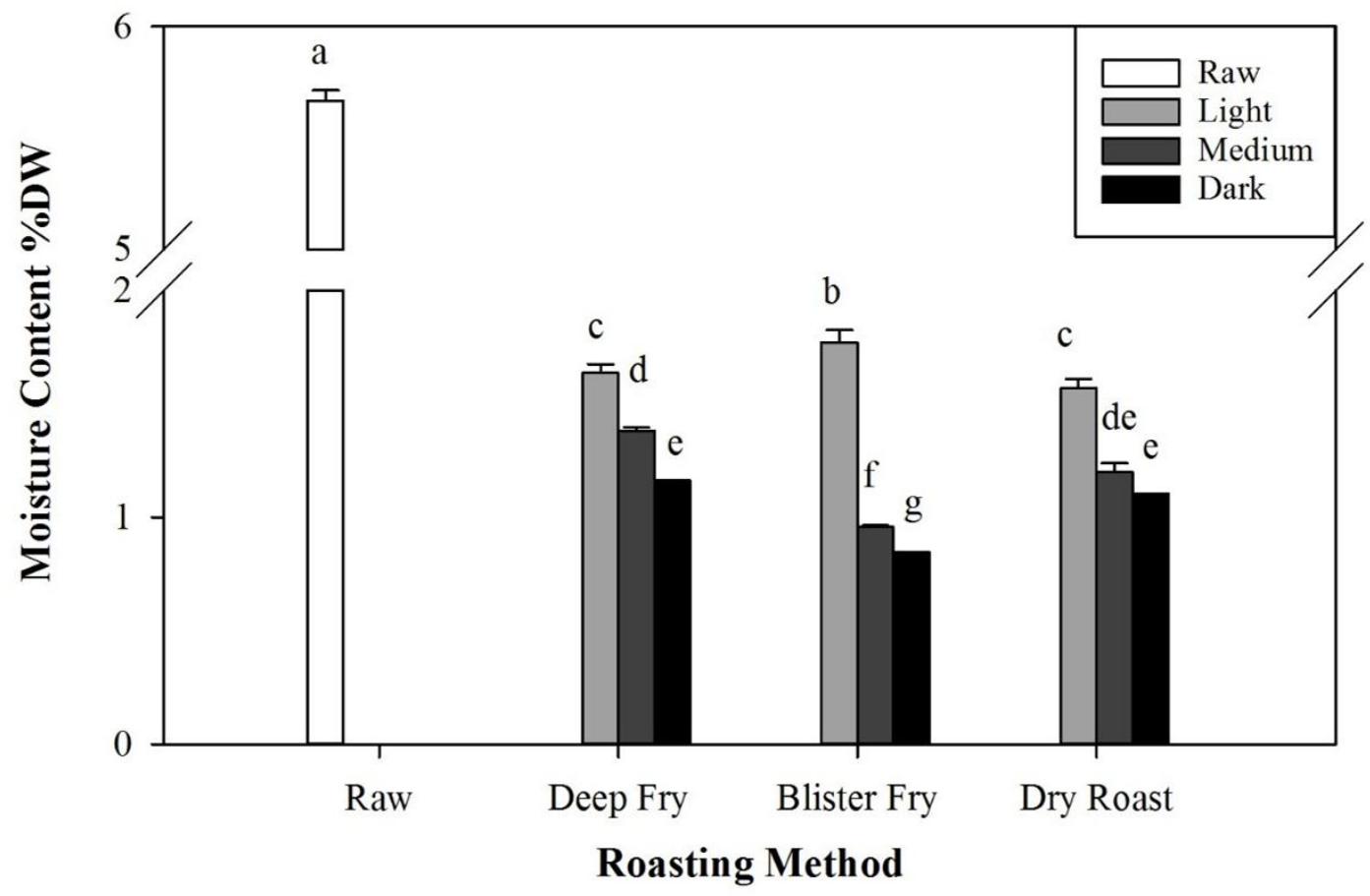




\section{Light}

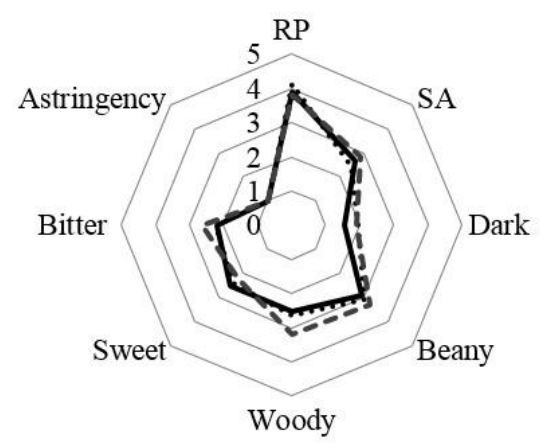

Medium

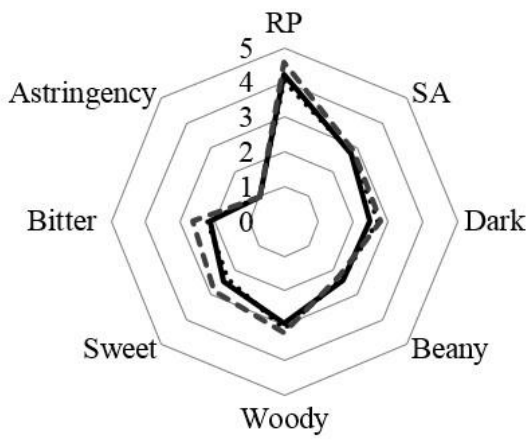

—Deep …. Blister ---Dry
Dark

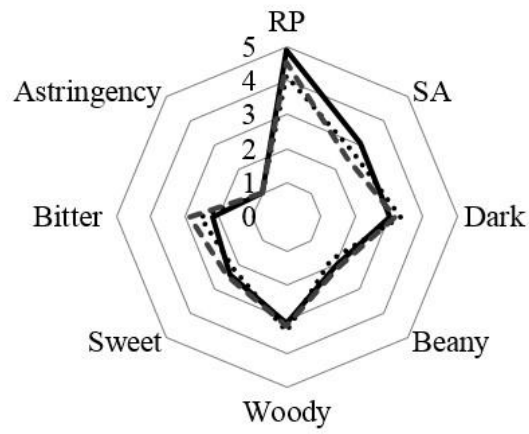




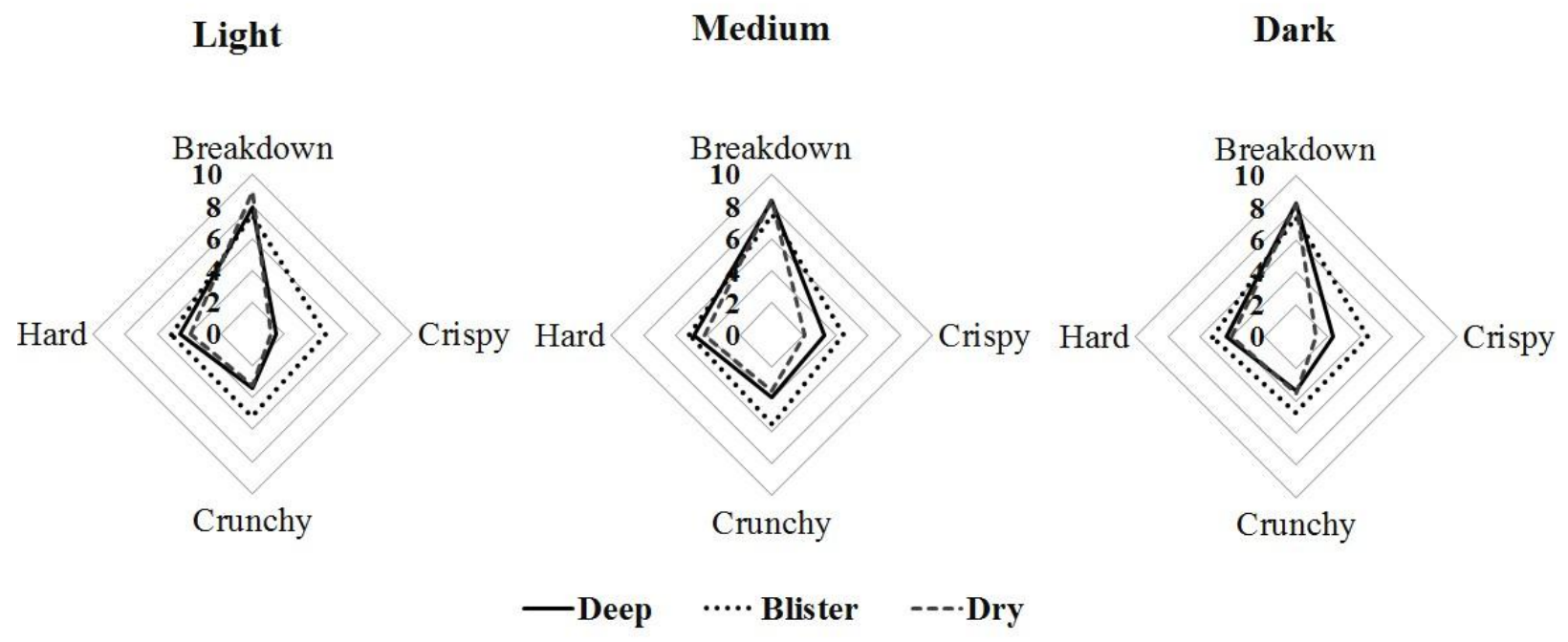



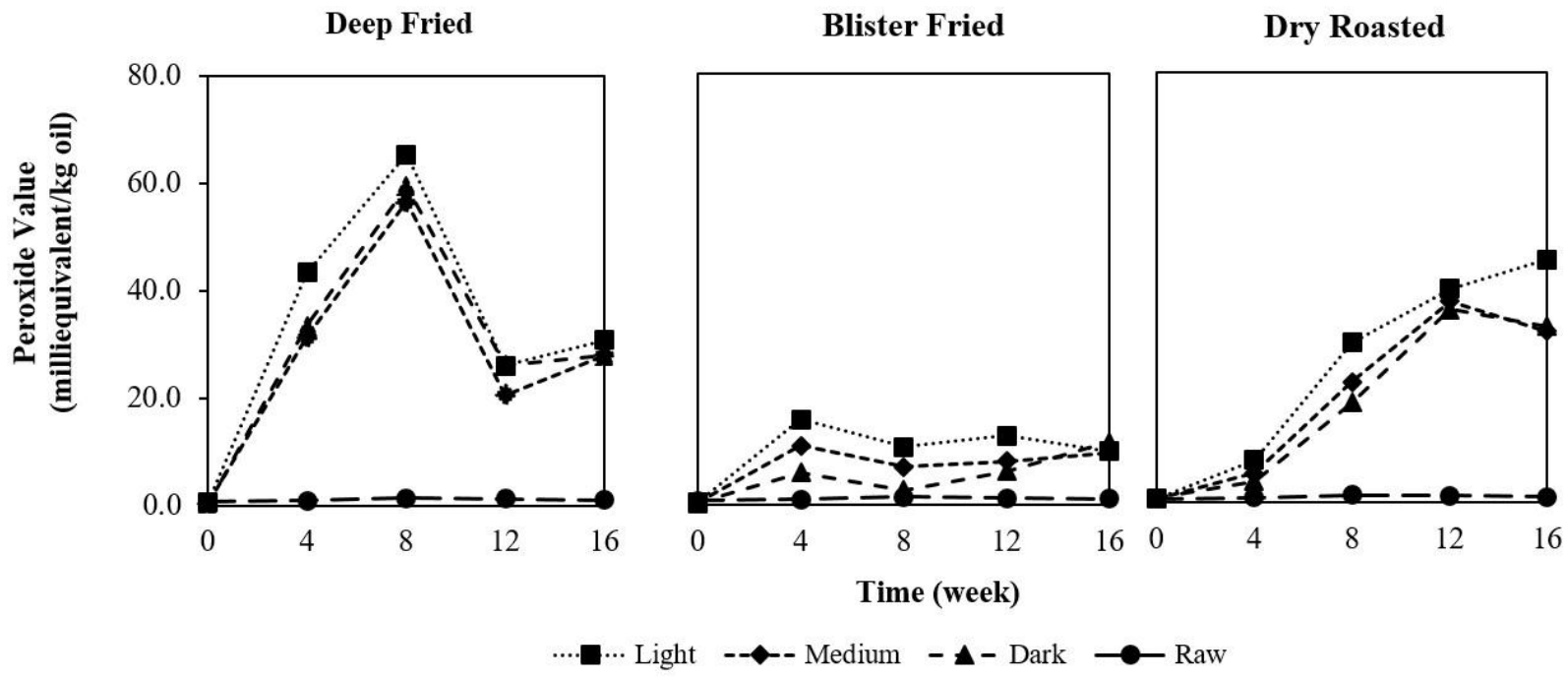


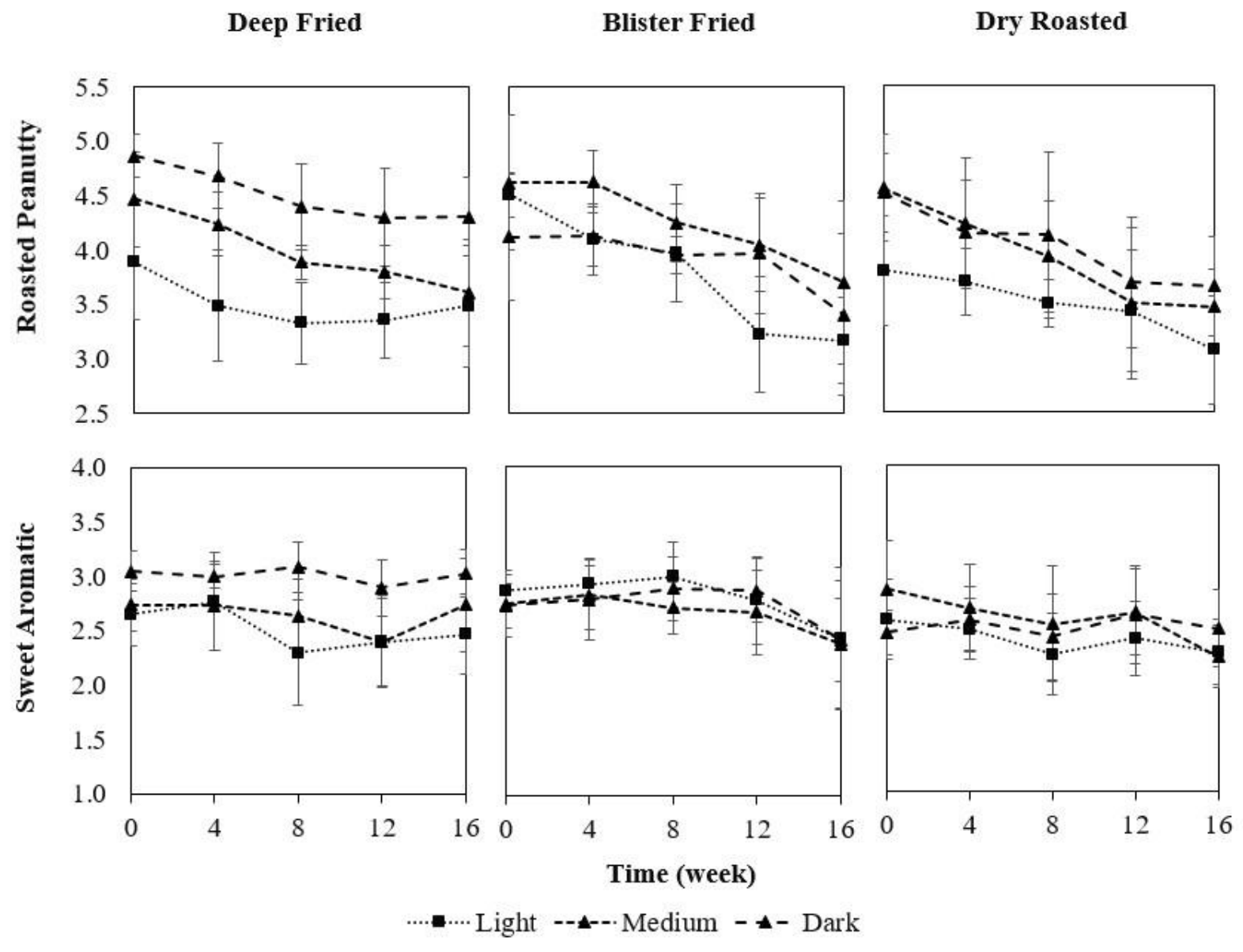



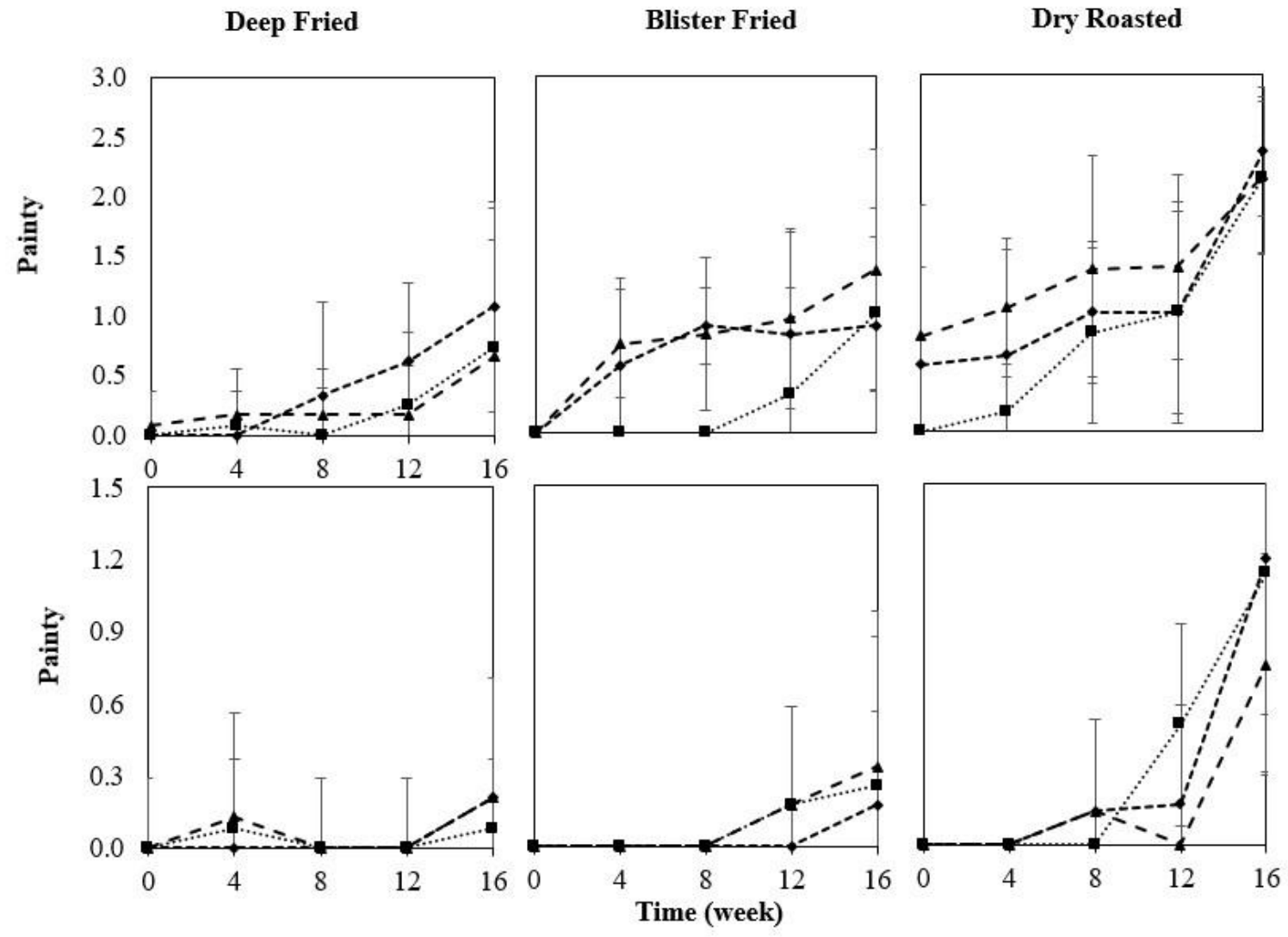

........ Light 
Table 1. Roasting time used for each treatment to achieve equivalent color roasting of light, medium, and dark at average surface Hunter L values of $53.0 \pm 1.0,48.5 \pm 1.0$, and $43.0 \pm 1.0$, respectively.

\begin{tabular}{lccc}
\hline & Deep Fry & Blister Fry & Dry Roast \\
\hline Light & 1.3 & 3.0 & 11.9 \\
Medium & 1.6 & 3.5 & 14.0 \\
Dark & 2.0 & 4.3 & 17.0 \\
\hline
\end{tabular}

